\title{
Minireview
}

\section{Clinical pharmacology of cancer therapies in older adults}

\author{
A Hurria*, and SM Lichtman² \\ 'The Department of Medical Oncology and Therapeutics Research, City of Hope, Duarte, CA 910 I0, USA; ${ }^{2}$ Memorial Sloan-Kettering Cancer Center, \\ Commack, NY II725, USA
}

This abbreviated review outlines the physiologic changes associated with aging, and examines how these changes may affect the pharmacokinetics and pharmacodynamics of anticancer therapies. We also provide an overview of studies that have been conducted evaluating the pharmacology of anticancer therapies in older adults, and issue a call for further research.

British Journal of Cancer (2008) 98, 5 I7-522. doi: I 0.1038/sj.bjc.660420 I www.bjcancer.com

Published online 5 February 2008

(c) 2008 Cancer Research UK

Keywords: pharmacokinetics; older patient; geriatric oncology; cancer therapy

Cancer is a disease of older adults. Approximately 60\% of cancer diagnoses and $70 \%$ of cancer mortalities occur in individuals age 65 and older (Yancik and Ries, 2000). As the general population ages and life expectancy increases, the number of older adults with cancer is growing.

Several unique challenges arise in caring for older adults with cancer. In particular, the physiologic changes associated with aging can have an impact on the pharmacokinetics and pharmacodynamics of cancer therapies. The effects of these age-related changes on drug dosing and tolerance have been understudied, as clinical trials that set the standards for oncology care and drug approval have typically focused on a younger patient population (Hutchins et al, 1999; Talarico et al, 2004). Few studies have included patients who are frail or who have a poor performance status (Table 1).

In this review, we provide an overview of the physiologic changes that accompany aging that may have an impact on the pharmacology of anticancer therapies. We also discuss recent studies evaluating the pharmacology of anticancer therapies in older adults.

\section{PHYSIOLOGIC CHANGES WITH AGING}

Aging is a heterogenous process; however, some characteristic changes in physiology and organ function can have an impact on the pharmacology of anticancer therapy. For example, age-related changes in the gastrointestinal tract may affect drug absorption. These changes include a decrease in splanchnic blood flow, gastrointestinal motility, secretion of digestive enzymes, and mucosal atrophy (Yuen, 1990; Baker and Grochow, 1997). With increasing age, hepatic mass decreases and there is a decrease in the cytochrome p450 content in liver biopsies, although the impact of these declines on hepatic function remains controversial (Sotaniemi et al, 1997; Shah, 2004; Sawhney et al, 2005).

\footnotetext{
* Correspondence: Dr A Hurria, City of Hope, I500 E. Duarte Road, Duarte, CA910I0, USA. E-mail: ahurria@coh.org or

Dr SM Lichtman, Memorial Sloan-Kettering Cancer Center, 650 Commack Road, Commack, NY I I725, USA.

E-mail: lichtmas@mskcc.org

Received 6 July 2007; revised 3 December 2007; accepted 20 December 2007; published online 5 February 2008
}

There is a decrease in renal mass and renal blood flow with aging (Vestal, 1997). These age-related changes in renal function could affect the pharmacology of anticancer drugs. A serum creatinine is often used to approximate renal function in younger adults; however, it is a poor indicator of renal function in older adults because of a decrease in muscle mass with age (FehrmanEkholm and Skeppholm, 2004). On average, the glomerular filtration rate decreases by approximately $0.75 \mathrm{ml} \mathrm{min}^{-1}$ year $^{-1}$ after age 40; however, this decrease is not universal, and approximately one-third of all patients will have no change in creatinine clearance with age (Lindeman et al, 1985). Various equations have been used to estimate glomerular filtration rate, including the Cockcroft/Gault, Jeliffe, Wright, and MDRD (modification of diet in renal disease) formulas. The Cockcroft/Gault and Jeliffe formulas have primarily been validated in younger patients without renal disease (Burkhardt et al, 2002; Rimon et al, 2004). The Wright formula is more accurate than the Cockcroft/ Gault formula in patients with a glomerular filtration rate of $>50$ (Marx et al, 2004). The MDRD formula is more accurate than other formulas in patients with chronic renal disease. This formula takes into account age, sex, ethnicity, serum creatinine, blood urea nitrogen, and albumin (Levey et al, 1999; Lichtman et al, 2007).

With increasing age, body composition changes, body fat increases and total body water decreases. This in turn increases the volume distribution of drugs that are lipid soluble and decreases the volume distribution of drugs that are water soluble. Hypoalbuminaemia and anaemia can lead to an increase in the volume distribution of drugs that are bound to albumin or haemoglobin, respectively. There is also an increase in bone marrow fat and a decrease in bone marrow reserve with age. This decrease in bone marrow reserve places older adults at increased risk for myelosuppressive complications from chemotherapy (Vestal, 1997).

Each of these physiologic changes that accompany aging could affect the pharmacokinetics and pharmacodynamics of anticancer therapies.

\section{CANCER THERAPY STUDIES IN OLDER ADULTS}

Several recent studies have examined the effects of age-related changes on the pharmacokinetics and pharmacodynamics of common cancer therapies. 
Table I Impact of age on the pharmacokinetic (pK) studies of chemotherapy drugs

\begin{tabular}{|c|c|c|c|c|}
\hline Author & Drug & Ages & pK analysis (n) & Results \\
\hline Lichtman et al (2006) & Paclitaxel & $55-86$ & 153 & Age-related decrease in clearance \\
\hline Fidias et al (200I) & Paclitaxel & $70-85$ & 13 & No age-related difference in pK \\
\hline Smorenburg et al (2003) & Paclitaxel & $22-84$ & 23 & Age-related decrease in clearance \\
\hline Slaviero et al (2004) & Docetaxel & $40-83$ & 54 & No age-related difference in pK \\
\hline Hurria et al (2006) & Docetaxel & $66-84$ & 19 & No age-related difference in pK \\
\hline Minami et al 2004 & Docetaxel and cisplatin & $39-86$ & 52 & No age-related difference in pK \\
\hline ten Tije et al (2005) & Docetaxel & $26-80$ & 40 & No age-related difference in $\mathrm{pK}$ \\
\hline Graham et al (2000) & Oxaliplatin & $26-72$ & 25 & No age-related difference in pK \\
\hline Jen et al (2000) & Temozolomide & $18-82$ & 445 & No age-related difference in pK \\
\hline Sorio et al (1997) & Vinorelbine & $66-81$ & 10 & No age-related difference in $\mathrm{pK}$ \\
\hline Gauvin et al (2000) & Vinorelbine & $65-79$ & 12 & Age-related decrease in clearance \\
\hline Milano et al (1992) & 5-Fluorouracil & $25-91$ & 380 & No age-related difference in pK \\
\hline Cassidy et al (1999) & Capecitabine & $41-80$ & 25 & No age-related difference in pK \\
\hline Toffoli et al (200I) & Etoposide & $50-83$ & 50 & No age-related difference in $\mathrm{pK}$ \\
\hline Miller et al (1997) & Etoposide and cisplatin & $<50-70+^{\mathrm{a}}$ & 106 & Age-related decrease in clearance \\
\hline Ando et alet al (1999) & Etoposide & $75-84$ & 12 & No age-related difference in pK \\
\hline Li and Gwilt (2003) & Doxorubicin & $12-74$ & 56 & Age-related decrease in Clearance \\
\hline Dees et al (2000) & Doxorubicin and cyclophosphamide & a & 24 & No age-related difference in $\mathrm{pK}$ \\
\hline
\end{tabular}

${ }^{\mathrm{a}}$ Exact age range not specified.

\section{Taxanes}

Taxanes are primarily metabolised hepatically. The pharmacokinetics of paclitaxel $175 \mathrm{mg} \mathrm{m}^{-2}$ given every 3 weeks was evaluated in 153 patients, ages 55-86. With higher age, there was an increase in the area under the curve (AUC) of paclitaxel and a decrease in drug clearance. This translated into an age-related increase in grade 3 neutropenia and lower absolute neutrophil count (ANC) nadir; however, there was no increase in the incidence of fever, hospitalisation, or need for intravenous antibiotics (Lichtman et al, 2006). Common comorbid medical conditions in older adults may impact tolerance to cancer therapy. For example, patients with diabetic neuropathy may be at increased risk for neurotoxicity to taxanes (Rowinsky et al, 1993).

The pharmacokinetics of docetaxel at $75 \mathrm{mg} \mathrm{m}^{-2}$ every 3 weeks was evaluated in 40 patients. There was no significant difference in the pharmacokinetics of docetaxel in patients older or younger than age 65; however, older adults were more likely to experience febrile neutropenia and grade 4 neutropenia (ten Tije et al, 2005). A population pharmacokinetics study of 640 patients who received docetaxel demonstrated a small overall impact related to age, but a large impact of abnormal liver function tests on docetaxel clearance. On the basis of these data, the authors recommended that dose adjustments be made in patients with abnormal liver function tests; however, no specific dose adjustment was recommended based on age (Bruno et al, 2001).

Studies evaluating the pharmacokinetics and pharmacodynamics of weekly paclitaxel and docetaxel have yielded conflicting results (Fidias et al, 2001; Smorenburg et al, 2003; Minami et al, 2004; Slaviero et al, 2004; Hurria et al, 2006). The majority of these studies revealed no significant age-related differences in the pharmacokinetics of weekly taxanes; however, one small study $(N=8)$ noted a $50 \%$ decrease in the clearance of unbound paclitaxel with increasing age (Smorenburg et al, 2003).

A newer formulation of taxane, nab-paclitaxel, is albuminbound and Cremophor-free, eliminating the need for steroid premedication. This makes it an attractive option for older adults, particularly those with comorbidities such as diabetes, which can be exacerbated with steroid premedication (Nyman et al, 2005). To date, no studies have been conducted into age-related changes in the pharmacokinetics of nab-paclitaxel, and this offers an important area for future research.

\section{Alkylating agents}

Cisplatin and carboplatin Both cisplatin and carboplatin rely on renal clearance and have a similar mechanism of action. The clearance of the drugs is triphasic in nature, consisting of a distribution half-life (13 min for cisplatin; $22 \mathrm{~min}$ for carboplatin), elimination half-life (43 min for cisplatin; $116 \mathrm{~min}$ for carboplatin), and terminal half-life (5.4 days for cisplatin; 5.8 days for carboplatin). Potential cisplatin toxicities that require early evaluation, dose modification, and/or treatment in older adults include nephrotoxicity, nausea and vomiting, electrolyte abnormalities, ototoxicity, myelosuppression, and peripheral neuropathy. Cisplatin can be directly nephrotoxic to the renal tubules; therefore, it must be used with caution in older adults who may already have impaired renal function. The dose of cisplatin should be adjusted if the glomerular filtration rate is $30-50 \mathrm{ml} \mathrm{min}^{-1}$, and it should not be given if creatinine clearance is $<30 \mathrm{ml} \mathrm{min}^{-1}$. The risk of cisplatin-induced nephrotoxicity can be ameliorated with intravenous hydration, and mannitol or furosemide diuresis. Carboplatin is not directly toxic to the renal tubules; however, since the drug is cleared renally, renal impairment will lead to increased drug levels. The clearance of carboplatin is linearly related to the patient's glomerular filtration rate. The Calvert formula, which takes into account a patient's glomerular filtration rate, is used to calculate the dose of carboplatin based on the desired AUC (Go and Adjei, 1999). A study of platinum-based chemotherapy for non-small cell lung cancer demonstrated that older patients were at increased risk for toxicity. In particular, compared with younger patients, older women were more likely to lose weight and older men were more likely to experience neuropsychiatric side effects and leucopenia (Langer et al, 2002).

Oxaliplatin Oxaliplatin is a platinum compound that is increasingly being used for the treatment of colon cancer. The most common toxicities include myelosuppression, nausea/vomiting, and neuropathy. A pharmacokinetic study of oxaliplatin in 25 patients between the ages of 26 and 72 demonstrated no association between oxaliplatin pharmacokinetics and age; however, the clearance of oxaliplatin was associated with glomerular filtration rate (Graham et al, 2000). A pharmacokinetic study of oxaliplatin performed in 37 patients between the ages of 32 and 86 , with varying degrees of renal dysfunction, and demonstrated an 
association between decreased creatinine clearance and decrease in the clearance of ultra-filterable platinum; however, there was no significant increase in side effects in patients with mild to moderate renal dysfunction. Therefore, the authors concluded that dose reductions were unnecessary in patients with a creatinine clearance of $\geqslant 20 \mathrm{ml} \mathrm{min}^{-1}$ (Takimoto et al, 2003). The impact of severe renal impairment on the clearance of oxaliplatin still remains unknown. There is no significant alteration in the clearance of oxaliplatin in patients with liver dysfunction (Doroshow et al, 2003).

Temozolomide Temozolomide is administered orally, and food decreases its absorption. The impact of age on the pharmacokinetics of temozolomide was evaluated in a cohort of 445 patients with a mean age of 50 (range $18-82$ ) who were enrolled in phase I and II studies. There was no significant association between patient age and the pharmacokinetics of temozolomide; however, there was an association of age, female gender, and temozolomide exposure with myelosuppression. The most important factor influencing the clearance of temozolomide was body surface area: increased body surface area was associated with increased clearance (Jen et al, 2000).

\section{Vinca alkaloids}

Vinorelbine The vinca alkaloid, vinorelbine, is primarily excreted through the biliary tract. Dose adjustment in patients with severe biliary disease has been recommended. Two studies of small sample size evaluated the impact of age on the pharmacokinetics of vinorelbine, and yielded conflicting results. Sorio et al (1997) studied the pharmacokinetics of vinorelbine in 10 patients age $\geqslant 65$ and found no age-related change in pharmacokinetics or toxicity. In contrast, Gauvin et al (2000) evaluated the pharmacokinetics of vinorelbine in 12 patients age $\geqslant 65$ and found a significant age-related decrease in vinorelbine clearance, estimated as a $30-40 \%$ clearance decrease for patients age $\geqslant 70$. An increase in the AUC of vinorelbine was associated with an increased risk of haematologic toxicity (Gauvin et al, 2000). Further studies regarding the impact of age on the pharmacokinetics and pharmacodynamics of vinorelbine are needed.

\section{Antimetabolites}

5-fluorouracil The antimetabolite, 5-fluorouracil (5FU), is metabolised hepatically. Its pharmacokinetics was evaluated in a cohort of 380 patients ages 25-91, but no significant impact of age was found. However, there were differences in 5FU clearance by gender. In particular, women had a significantly lower clearance of 5FU because of lower dihydropyrimidine dehydrogenase activity, the key enzyme involved in the clearance of 5FU (Milano et al, 1992). Other studies have demonstrated that older patients receiving $5 \mathrm{FU}$ are at increased risk for leucopenia and mucositis (Popescu et al, 1999; Sargent et al, 2001).

Capecitabine The oral fluoropyrimidine, capecitabine, is absorbed in the gastrointestinal tract, then enzymatically converted to 5FU in the liver. Caution must be used in patients with liver dysfunction, as there are no clear dosing guidelines for capecitabine in patients with severe hepatic impairment. Capecitabine and its metabolites are primarily excreted in the urine, and a pharmacokinetics study of capecitabine in patients with varying degrees of renal dysfunction demonstrated that they have increased systemic exposure to capecitabine and an increased risk of grade 3 or 4 toxicity (Poole et al, 2002). The dose of capecitabine needs to be adjusted if a patient's creatinine clearance is $<50 \mathrm{ml} \mathrm{min}^{-1}$, and capecitabine should not be prescribed in patients with a creatinine clearance $<30 \mathrm{ml} \mathrm{min}^{-1}$.
There is a potential for drug interactions with capecitabine. Concomitant exposure to capecitabine and warfarin leads to exaggerated anticoagulant activity (Camidge et al, 2005). Thus, the international normalised ratio needs to be monitored carefully when prescribing capecitabine to a patient who takes warfarin. In addition, there is a potential for interaction between folate supplementation and capecitabine. In a study of patients with colorectal cancer receiving capecitabine, those with higher pretreatment levels of serum folate experienced greater toxicity during cycle 1 and over the treatment period (Sharma et al, 2006).

Methotrexate Methotrexate, a component of the CMF (cyclophosphamide, methotrexate, $5 \mathrm{FU}$ ) regimen for treatment of breast cancer, is associated with an increased risk of toxicity in older adults. This antifolate is eliminated renally and the clearance of methotrexate decreases with decreased creatinine clearance; therefore, the dosing of methotrexate should be adjusted based on renal function (Bressolle et al, 1998). In a study by Gelman and Taylor (1984), the age-related increase in toxicity with CMF was eliminated by modifying the doses of methotrexate and cyclophosphamide based on renal function, and empirically decreasing the dose of 5FU by two-thirds. However, it is not known if this approach affects the efficacy of the therapy (Gelman and Taylor, 1984). Caution is required in prescribing methotrexate for patients with metastatic cancer who have ascites or pleural effusion, which can lead to prolonged elimination of methotrexate and increased toxicity.

Cytosine arabinoside Cytosine arabinoside (ara-C) is rapidly eliminated from plasma by deamination. Approximately $70-80 \%$ of a given dose is excreted as ara-U. Older adults are at increased risk for toxicity with high-dose ara- $\mathrm{C}$ because of age-related alterations in renal function. In particular, risk factors for ara-Cassociated neurotoxicity include a creatinine $\geqslant 1.2 \mathrm{mg} \mathrm{dl}^{-1}$, age $\geqslant 40$, and alkaline phosphatase $\geqslant 3$ times normal (Rubin et al, 1992). The incidence of neurotoxicity can be reduced if dosing takes renal function into account (Smith et al, 1997).

\section{Topoisomerase inhibitors}

Etoposide Etoposide is a topoisomerase II inhibitor. The clearance of etoposide is slower in patients with impaired renal function (Toffoli et al, 2001). In contrast, there is no significant difference in the pharmacokinetics of etoposide in patients with impaired hepatic function (Aita et al, 1999; Toffoli et al, 2001). Studies evaluating the impact of age on the pharmacokinetics of etoposide have produced conflicting results. Toffoli et al (2001) studied 50 patients ranging in age from 50 to 83 . They found no impact of age on the pharmacokinetics of etoposide when taking creatinine clearance into account. Miller et al (1997) evaluated 106 patients who received etoposide in combination with cisplatin, and reported that older age was associated with an increase in free and trough etoposide concentrations. Ando et al (1999) evaluated the pharmacokinetics of oral etoposide in 12 patients ranging from age 75 to 84 , and detected no difference in the etoposide pharmacokinetics of this group in comparison with historical data from younger patients. However, they did find that older patients were at increased risk for myelosuppressive complications.

\section{Anthracyclines}

Doxorubicin Doxorubicin is primarily metabolised hepatically. Li and Gwilt (2003) evaluated the impact of age on the pharmacokinetics of doxorubicin in 56 patients between the ages of 12 and 74. Increased age was associated with decreased clearance of doxorubicin. Dees et al (2000) evaluated the pharmacokinetics of AC (doxorubicin $60 \mathrm{mg} \mathrm{m}^{-2}$ and cyclophosphamide $600 \mathrm{mg} \mathrm{m}^{-2}$ ) in 24 patients. There was no impact of age on the clearance of 
doxorubicin or cyclophosphamide; however, older adults were at increased risk for myelosuppression. Age is a known risk factor for congestive heart failure in older adults who receive doxorubicin. Swain et al (2003) evaluated a cohort of 630 patients who received doxorubicin $v s$ placebo in three phase III clinical trials, and found an association between older age and the risk of congestive heart failure after a cumulative doxorubicin dose of $400 \mathrm{mg} \mathrm{m}^{-2}$.

\section{FURTHER RESEARCH}

There are limited data available regarding the impact of age on the pharmacokinetics and pharmacodynamics of targeted therapies. This area needs much more research. Some data do suggest an association between age and risk of toxicity with targeted therapies. For example, increasing age is a risk factor for congestive heart failure associated with trastuzumab, the humanised monoclonal antibody that targets the HER-2 (human epidermal growth factor receptor 2) protein. This was demonstrated in the NSABP B31 study of doxorubicin and cyclophosphamide followed by paclitaxel with or without trastuzumab for the adjuvant treatment of patients with HER-2/neu-positive breast cancer. In this study, risk factors for trastuzumab-associated congestive heart failure included older age (defined as age $\geqslant 50$ ) and a lower left ventricular ejection (defined as post-AC ejection fraction of $50-54 \%)$. There was a $20 \%$ (95\% CI, 11.1-35.9), 3-year cumulative incidence of congestive heart failure in patients age $\geqslant 50$ who received adjuvant trastuzumab with a left ventricular ejection fraction of $50-54 \%$ after AC (Tan-Chiu et al, 2005). It is unclear whether this was solely a pharmacodynamic effect of trastuzumab on cardiac function or whether an age-related change in trastuzumab pharmacokinetics may also have played a role.

Another example of age-related toxicity with targeted therapy is seen among patients receiving bevacizumab, the humanised monoclonal antibody that inhibits vascular endothelial growth factor (VEGF). A retrospective pooled analysis of five randomised studies in 1745 patients demonstrated that patients age $\geqslant 65$, who were treated with chemotherapy and bevacizumab, had an increased risk of arterial thromboembolic events compared with those age $<65$ (7.1 vs 2.5\%). Risk factors for development of an arterial thromboembolic event included age $>65(P=0.01)$ and history of a prior arterial thromboembolic event $(P<0.001)$ (Scappaticci et al, 2007).

A phase III study (E3200) in patients with metastatic colon cancer receiving bevacizumab and $5 \mathrm{FU}$, leucovorin, and oxaliplatin demonstrated that patients age $\geqslant 65$ had an increased risk of gastrointestinal side effects and fatigue compared with younger individuals. In addition, in a phase III study (E4599) of patients with advanced non-small cell lung cancer who received paclitaxel and carboplatin, and who were randomised to receive or not to receive bevacizumab, demonstrated that older adults were at increased risk for developing proteinuria.

There are limited data regarding the age-related pharmacokinetics or pharmacodynamics of other commonly used targeted agents, such as erlotinib, cetuximab, and sunitinib. A phase II study of erlotinib as first line therapy for patients age 70 and older with advanced non-small cell lung cancer demonstrated that $12 \%$ of patients on the study required discontinuation of therapy, most commonly due to interstitial lung disease, dehydration, and diarrhoea. There was one treatment related death attributed to interstitial lung disease. This trial did not include a direct comparison of older and younger adults; however, the rate of treatment discontinuation reported in this trial was higher than the rate of treatment discontinuation reported in previous clinical trials of patients with a younger mean age (Jackman et al, 2007).

The mechanism behind this age-related increase in side effects with targeted therapies is unclear, and studies are needed to address these questions.

\section{CONCLUSIONS}

Despite the aging of the population and the association of cancer with aging, the pharmacokinetics and pharmacodynamics of anticancer therapies have been understudied in older adults. Most of the studies performed to date have not demonstrated significant age-related differences in the pharmacokinetics of cancer therapies; however, the majority of the studies consisted of small sample size and would not be able to detect a subtle change. In addition, chronologic age is only one factor to consider. Other measures of physiological age that may affect tolerance to cancer therapy in older adults should also be captured, including functional status, other comorbid medical conditions, concomitant medications, nutritional status, and renal and hepatic function. As new drugs are introduced into oncology treatment, phase II studies of the pharmacokinetics and pharmacodynamics of cancer therapies in older adults, which captures all of these factors, are needed in order to determine the optimum treatment for this growing population of older patients with cancer.

\section{ACKNOWLEDGEMENTS}

We thank Carol A Pearce for editing this paper. Dr Hurria is supported by K23 AG026749-01 Paul Beeson Career Development Award in Aging Research (recipient: Arti Hurria, MD) and American Society of Clinical Oncology-Association of Specialty Professors-Junior Development Award in Geriatric Oncology (recipient: Arti Hurria, MD).

\section{REFERENCES}

Aita P, Robieux I, Sorio R, Tumolo S, Corona G, Cannizzaro R, Colussi AM, Boiocchi M, Toffoli G (1999) Pharmacokinetics of oral etoposide in patients with hepatocellular carcinoma. Cancer Chemother Pharmacol 43: 287 - 294

Ando M, Minami H, Ando Y, Sakai S, Shimono Y, Sugiura S, Saka H, Shimokata K, Hasegawa Y (1999) Pharmacological analysis of etoposide in elderly patients with lung cancer. Clin Cancer Res 5: 1690-1695

Baker SD, Grochow LB (1997) Pharmacology of cancer chemotherapy in the older person. Clin Geriatr Med 13: 169-183

Bressolle F, Bologna C, Kinowski JM, Sany J, Combe B (1998) Effects of moderate renal insufficiency on pharmacokinetics of methotrexate in rheumatoid arthritis patients. Ann Rheum Dis 57: 110-113

Bruno R, Vivier N, Veyrat-Follet C, Montay G, Rhodes GR (2001) Population pharmacokinetics and pharmacokinetic-pharmacodynamic relationships for docetaxel. Invest New Drugs 19: $163-169$
Burkhardt H, Bojarsky G, Gretz N, Gladisch R (2002) Creatinine clearance, Cockcroft-Gault formula and cystatin C: estimators of true glomerular filtration rate in the elderly? Gerontology 48: 140-146

Camidge R, Reigner B, Cassidy J, Grange S, Abt M, Weidekamm E, Jodrell D (2005) Significant effect of capecitabine on the pharmacokinetics and pharmacodynamics of warfarin in patients with cancer. J Clin Oncol 23: $4719-4725$

Dees EC, O'Reilly S, Goodman SN, Sartorius S, Levine MA, Jones RJ, Grochow LB, Donehower RC, Fetting JH (2000) A prospective pharmacologic evaluation of age-related toxicity of adjuvant chemotherapy in women with breast cancer. Cancer Invest 18: $521-529$

Doroshow JH, Synold TW, Gandara D, Mani S, Remick SC, Mulkerin D, Hamilton A, Sharma S, Ramanathan RK, Lenz HJ, Graham M, Longmate J, Takimoto CH, Ivy P (2003) Pharmacology of oxaliplatin in solid 
tumor patients with hepatic dysfunction: a preliminary report of the national cancer institute organ dysfunction working group. Semin Oncol 30: $14-19$

Fehrman-Ekholm I, Skeppholm L (2004) Renal function in the elderly ( $>70$ years old) measured by means of iohexol clearance, serum creatinine, serum urea and estimated clearance. Scand J Urol Nephrol 38: 73-77

Fidias P, Supko JG, Martins R, Boral A, Carey R, Grossbard M, Shapiro G, Ostler P, Lucca J, Johnson BE, Skarin A, Lynch TJ (2001) A phase II study of weekly paclitaxel in elderly patients with advanced non-small cell lung cancer. Clin Cancer Res 7: 3942 - 3949

Gauvin A, Pinguet F, Culine S, Astre C, Gomeni R, Bressolle F (2000) Bayesian estimate of vinorelbine pharmacokinetic parameters in elderly patients with advanced metastatic cancer. Clin Cancer Res 6: $2690-2695$

Gelman RS, Taylor IV SG (1984) Cyclophosphamide, methotrexate, and 5fluorouracil chemotherapy in women more than 65 years old with advanced breast cancer: the elimination of age trends in toxicity by using doses based on creatinine clearance. J Clin Oncol 2: 1404-1413

Go RS, Adjei AA (1999) Review of the comparative pharmacology and clinical activity of cisplatin and carboplatin. J Clin Oncol 17: 409-422

Graham MA, Lockwood GF, Greenslade D, Brienza S, Bayssas M, Gamelin E (2000) Clinical pharmacokinetics of oxaliplatin: a critical review. Clin Cancer Res 6: $1205-1218$

Hurria A, Fleming MT, Baker SD, Kelly WK, Cutchall K, Panageas K, Caravelli J, Yeung H, Kris MG, Gomez J, Miller VA, D’Andrea G, Scher HI, Norton L, Hudis C (2006) Pharmacokinetics and toxicity of weekly docetaxel in older patients. Clin Cancer Res 12: 6100-6105

Hutchins LF, Unger JM, Crowley JJ, Coltman Jr CA, Albain KS (1999) Underrepresentation of patients 65 years of age or older in cancertreatment trials. $N$ Engl J Med 341: $2061-2067$

Jackman DM, Yeap BY, Lindeman NI, Fidias P, Rabin MS, Temel J, Skarin AT, Meyerson M, Holmes AJ, Borras AM, Freidlin B, Ostler PA, Lucca J, Lynch TJ, Johnson BE, Janne PA (2007) Phase II clinical trial of chemotherapy-naive patients $>$ or $=70$ years of age treated with erlotinib for advanced non-small-cell lung cancer. J Clin Oncol 25: $760-766$

Jen JF, Cutler DL, Pai SM, Batra VK, Affrime MB, Zambas DN, Heft S, Hajian G (2000) Population pharmacokinetics of temozolomide in cancer patients. Pharm Res 17: 1284-1289

Langer CJ, Manola J, Bernardo P, Kugler JW, Bonomi P, Cella D, Johnson DH (2002) Cisplatin-based therapy for elderly patients with advanced non-small-cell lung cancer: implications of eastern cooperative oncology group 5592, a randomized trial. J Natl Cancer Inst 94: 173-181

Levey AS, Bosch JP, Lewis JB, Greene T, Rogers N, Roth D (1999) A more accurate method to estimate glomerular filtration rate from serum creatinine: a new prediction equation. Modification of diet in renal disease study group. Ann Intern Med 130: $461-470$

Li J, Gwilt PR (2003) The effect of age on the early disposition of doxorubicin. Cancer Chemother Pharmacol 51: 395-402

Lichtman SM, Hollis D, Miller AA, Rosner GL, Rhoades CA, Lester EP, Millard F, Byrd J, Cullinan SA, Rosen DM, Parise RA, Ratain MJ, Egorin MJ (2006) Prospective evaluation of the relationship of patient age and paclitaxel clinical pharmacology: cancer and leukemia group B (CALGB 9762). J Clin Oncol 24: 1846-1851

Lichtman SM, Wildiers H, Launay-Vacher V, Steer C, Chatelut E, Aapro M (2007) International society of geriatric oncology (SIOG) recommendations for the adjustment of dosing in elderly cancer patients with renal insufficiency. Eur I Cancer 43: 14-34

Lindeman RD, Tobin J, Shock NW (1985) Longitudinal studies on the rate of decline in renal function with age. J Am Geriatr Soc 33: 278-285

Marx GM, Blake GM, Galani E, Steer CB, Harper SE, Adamson KL, Bailey DL, Harper PG (2004) Evaluation of the Cockroft-Gault, Jelliffe and Wright formulae in estimating renal function in elderly cancer patients. Ann Oncol 15: 291 - 295

Milano G, Etienne MC, Cassuto-Viguier E, Thyss A, Santini J, Frenay M, Renee N, Schneider M, Demard F (1992) Influence of sex and age on fluorouracil clearance. I Clin Oncol 10: 1171 - 1175

Miller AA, Rosner GL, Ratain MJ, Hollis DR, Green MR, Schilsky RL (1997) Pharmacology of 21-day oral etoposide given in combination with i.v. cisplatin in patients with extensive-stage small cell lung cancer: a cancer and leukemia group B study (CALGB 9062). Clin Cancer Res 3: 719-725

Minami H, Ohe Y, Niho S, Goto K, Ohmatsu H, Kubota K, Kakinuma R, Nishiwaki Y, Nokihara H, Sekine I, Saijo N, Hanada K, Ogata H (2004) Comparison of pharmacokinetics and pharmacodynamics of docetaxel and Cisplatin in elderly and non-elderly patients: why is toxicity increased in elderly patients? J Clin Oncol 22: 2901 -2908
Nyman DW, Campbell KJ, Hersh E, Long K, Richardson K, Trieu V, Desai N, Hawkins MJ, Von Hoff DD (2005) Phase I and pharmacokinetics trial of ABI-007, a novel nanoparticle formulation of paclitaxel in patients with advanced nonhematologic malignancies. J Clin Oncol 23: $7785-7793$

Poole C, Gardiner J, Twelves C, Johnston P, Harper P, Cassidy J, Monkhouse J, Banken L, Weidekamm E, Reigner B (2002) Effect of renal impairment on the pharmacokinetics and tolerability of capecitabine (Xeloda) in cancer patients. Cancer Chemother Pharmacol 49: $225-234$

Popescu RA, Norman A, Ross PJ, Parikh B, Cunningham D (1999) Adjuvant or palliative chemotherapy for colorectal cancer in patients 70 years or older. J Clin Oncol 17: 2412-2418

Rimon E, Kagansky N, Cojocaru L, Gindin J, Schattner A, Levy S (2004) Can creatinine clearance be accurately predicted by formulae in octogenarian in-patients? QJM 97: 281 - 287

Rowinsky EK, Chaudhry V, Cornblath DR, Donehower RC (1993) Neurotoxicity of taxol. J Natl Cancer Inst 15: 107-115

Rubin EH, Andersen JW, Berg DT, Schiffer CA, Mayer RJ, Stone RM (1992) Risk factors for high-dose cytarabine neurotoxicity: an analysis of a cancer and leukemia group B trial in patients with acute myeloid leukemia. J Clin Oncol 10: $948-953$

Sargent DJ, Goldberg RM, Jacobson SD, Macdonald JS, Labianca R, Haller DG, Shepherd LE, Seitz JF, Francini G (2001) A pooled analysis of adjuvant chemotherapy for resected colon cancer in elderly patients. $N$ Engl J Med 345: 1091 - 1097

Sawhney R, Sehl M, Naeim A (2005) Physiologic aspects of aging: impact on cancer management and decision making, part I. Cancer J 11: 449-460

Scappaticci FA, Skillings JR, Holden SN, Gerber HP, Miller K, Kabbinavar F, Bergsland E, Ngai J, Holmgren E, Wang J, Hurwitz H (2007) Arterial thromboembolic events in patients with metastatic carcinoma treated with chemotherapy and bevacizumab. J Natl Cancer Inst 99: 1232-1239

Shah RR (2004) Drug development and use in the elderly: search for the right dose and dosing regimen (parts I and II). Br J Clin Pharmacol 58: $452-469$

Sharma R, Rivory L, Beale P, Ong S, Horvath L, Clarke SJ (2006) A phase II study of fixed-dose capecitabine and assessment of predictors of toxicity in patients with advanced/metastatic colorectal cancer. Br J Cancer 94: $964-968$

Shaywitz SE, Shaywitz BA, Pugh KR, Fulbright RK, Skudlarski P, Mencl WE, Constable RT, Naftolin F, Palter SF, Marchione KE, Katz L, Shankweiler DP, Fletcher JM, Lacadie C, Keltz M, Gore JC (1999) Effect of estrogen on brain activation patterns in postmenopausal women during working memory tasks. JAMA 281: $1197-1202$

Slaviero KA, Clarke SJ, McLachlan AJ, Blair EY, Rivory LP (2004) Population pharmacokinetics of weekly docetaxel in patients with advanced cancer. Br J Clin Pharmacol 57: 44-53

Smith GA, Damon LE, Rugo HS, Ries CA, Linker CA (1997) High-dose cytarabine dose modification reduces the incidence of neurotoxicity in patients with renal insufficiency. J Clin Oncol 15: 833-839

Smorenburg $\mathrm{CH}$, ten Tije AJ, Verweij J, Bontenbal M, Mross K, van Zomeren DM, Seynaeve C, Sparreboom A (2003) Altered clearance of unbound paclitaxel in elderly patients with metastatic breast cancer. Eur J Cancer 39: 196-202

Sorio R, Robieux I, Galligioni E, Freschi A, Colussi AM, Crivellari D, Saracchini S, Monfardini S (1997) Pharmacokinetics and tolerance of vinorelbine in elderly patients with metastatic breast cancer. Eur J Cancer 33: $301-303$

Sotaniemi EA, Arranto AJ, Pelkonen O, Pasanen M (1997) Age and cytochrome P450-linked drug metabolism in humans: an analysis of 226 subjects with equal histopathologic conditions. Clin Pharmacol Ther 61: $331-339$

Swain SM, Whaley FS, Ewer MS (2003) Congestive heart failure in patients treated with doxorubicin: a retrospective analysis of three trials. Cancer 97: $2869-2879$

Takimoto CH, Remick SC, Sharma S, Mani S, Ramanathan RK, Doroshow J, Hamilton A, Mulkerin D, Graham M, Lockwood GF, Ivy P, Egorin M, Schuler B, Greenslade D, Goetz A, Knight R, Thomas R, Monahan BP, Dahut W, Grem JL (2003) Dose-escalating and pharmacological study of oxaliplatin in adult cancer patients with impaired renal function: a national cancer institute organ dysfunction working group study. J Clin Oncol 21: 2664-2672

Talarico L, Chen G, Pazdur R (2004) Enrollment of elderly patients in clinical trials for cancer drug registration: a 7-year experience by the US food and drug administration. J Clin Oncol 22: 4626-4631 


\section{Clinical pharmacology of cancer therapies}

A Hurria and SM Lichtman

Tan-Chiu E, Yothers G, Romond E, Geyer Jr CE, Ewer M, Keefe D, Shannon RP, Swain SM, Brown A, Fehrenbacher L, Vogel VG, Seay TE, Rastogi P, Mamounas EP, Wolmark N, Bryant J (2005) Assessment of cardiac dysfunction in a randomized trial comparing doxorubicin and cyclophosphamide followed by paclitaxel, with or without trastuzumab as adjuvant therapy in node-positive, human epidermal growth factor receptor 2-overexpressing breast cancer: NSABP B-31. J Clin Oncol 23: $7811-7819$

ten Tije AJ, Verweij J, Carducci MA, Graveland W, Rogers T, Pronk T, Verbruggen MP, Dawkins F, Baker SD (2005) Prospective evaluation of the pharmacokinetics and toxicity profile of docetaxel in the elderly. J Clin Oncol 23: 1070-1077

Toffoli G, Corona G, Sorio R, Robieux I, Basso B, Colussi AM, Boiocchi M (2001) Population pharmacokinetics and pharmacodynamics of oral etoposide. Br J Clin Pharmacol 52: 511-519

Vestal RE (1997) Aging and pharmacology. Cancer 80: 1302-1310

Yancik R, Ries LA (2000) Aging and cancer in America. Demographic and epidemiologic perspectives. Hematol Oncol Clin North Am 14: 17-23

Yuen GJ (1990) Altered pharmacokinetics in the elderly. Clin Geriatr Med 6: $257-267$ 